\title{
Game-based learning and assessment for history education
}

\author{
Woo Hyun Lee ${ }^{1}$, Sang Yong Park² and Won Hyung Lee ${ }^{1, *}$ \\ 1 Graduate School of Advanced Imaging Science, Multimedia and Film, Chung-Ang University, 84 \\ Heukseok-ro, Dongjak-gu, Seoul, Korea; rockdog82@cau.ac.kr; whlee@cau.ac.kr \\ 2 Institute of Cultural Diversity Contents, Chung-Ang University, 84 Heukseok-ro, Dongjak-gu, Seoul, Korea; \\ psypher@cau.ac.kr \\ * Correspondence: whlee@cau.ac.kr
}

Citation: Lastname, F.; Lastname, F.;

Lastname, F. Title. Educ. Sci. 2021, 11, x. https://doi.org/10.3390/xxxxx

\begin{abstract}
Regardless of country and age, the importance of history education is always being emphasized. Although the importance of history education is being emphasized in Korea, there are many difficulties in getting students to understand history properly through school classes alone, and it is also difficult to attract students to participate in classes. The effectiveness of education using games has been proven 20 years ago, and the demand for game-based education is gradually increasing in the current education world, which is becoming more open. In this paper, based on the effects proven through research on the existing game-based education, the improvement of historical thinking ability, experiential history learning, and the problems of game-based education introduced in the ESN report and the discomfort of teachers who participated in the education were improved. A plan was suggested to select and use games suitable for basic education. In this thesis, we selected a history game with a clear historical and periodic background and without distortion of history, and experimented with teaching using games focusing on historical thinking and empirical history learning. The learning achievement of textbook-based education was compared.
\end{abstract}

Keywords: Re-enaction history learning; Game-based learning; historical thinking skills; historical game; historical education

\section{Introduction}

The importance of history education is emphasized regardless of country or culture. Rather, the more advanced countries, the more important the history is and do not spare support for history education. Korea, which is the only divided country and constantly controversial over history issues with neighboring countries, needs a lot of investment and interest in history education.

Attempts to use games for education have been steadily continuing since decades ago, and professor Jong Hyun Wi of Chung-Ang University has proven its effectiveness through various educational experiments such as mathematics[1], English[2], politics[3], and economics[4] under the concept of G-Learnging which introduced games into education. As such, studies on the use of games that have been effective in various subject areas, theories that combine them, and examples of actual class application have been conducted, while studies on the use of games in history subjects are insufficient. Educators who watched the evils of instillation-type education in the past produced various contents such as movies and cartoons to understand history through storytelling and used them in education. Game also puts storytelling as the most important factor in determining immersion, so history education, where storytelling is important[5], will be one of the subjects that will show the greatest advantage when used as a game.

\section{Use of games in the educational field}


Since educators communicate knowledge through interactions with students who are trainees, the means to inspire these students' concentration has become a subject of research regardless of the times. As one of these means, the concept of 'gamification' and 'game-based learning (GBL)' in today's classes is being developed in various directions because it was able to be effective by adding fun elements of the game. 'Gamification' is the concept of adding play elements to fields other than games, and is commonly used to give small-scale goals and rewards. For example, giving a quiz without scoring the results of study as a test is the most common gamification, and a Serious game that develops the content itself into a complete game also falls within the Gamification category. And 'Game-Based Learning (GBL)' is a concept that utilizes educational elements in a game, and is a way for learners to learn something while playing the game.

Gamification has been considered a promising future education approach in recent years, making it one of the most favored areas in academic research and development[6]. 'Game-based learning (GBL)' is a concept that utilizes the educational elements in the game, and the learner reaches the learning goal using a computer game that combines educational contents and games without the direct involvement of the teacher[7]. In addition, game-based learning acts as a tool for learners to learn something from interactive learning through audio-visual capabilities, animations, videos and games[8]. Serious games are games with a purpose not only to pursue entertainment elements, but to solve the real problems faced in reality[9]. However, At this time, Serious games are developing focusing only on educational efficacy[10][11][12], most learning content is to study the achievement effects of learning or training using research data on the achievements of Serious games or reports from public institutions in games, and takes the form of verifying the impact and performance of Serious games [13][14][15]. However, when planning to educate using actual games, it is necessary to discuss 'how many classes to teach', starting with the teacher installing the games selected to be used, so even if the efficacy of Serious games is academically proven, it is difficult to be used in actual education if accessibility is reduced[16]. Developing a game requires a lot of resources from graphics to sound, and a lot of advanced personnel capable of designing or coding depending on the size of the game. There is a limit to covering these costs without investment. However, investments are made mainly in areas of high profitability, and it is difficult to expect high profits from Serious games aimed at education.

Eui Jun Jeong said Serious games have an intentional purpose and should be purpose-oriented from the planning stage[17]. Serious games created for education already have excellent functions as educational materials to suit the purpose of development. The problem is that the effort to develop this great educational material takes tens or hundreds of times the effort of writing a single book. Compared to traditional education, Serious games can inspire concentration through the advantage of fun, but the marketability is inferior as the game itself is not a popular genre. Products with poor marketability do not make smooth investments, leading to a decline in game quality and productivity. Serious games with low productivity have a narrow range of choices, and because they are mainly used for academic purposes, they are not easily shared, so accessibility is also low.

Table 1. Problems of using games in education.

\begin{tabular}{cc}
\hline Rank & Reason \\
\hline 1 & Cost and licensing \\
2 & Timetable of the school \\
3 & Finding suitable games \\
4 & Attitudes of other teachers \\
5 & Training and support \\
6 & Inappropriate content \\
\hline
\end{tabular}




\begin{tabular}{cc}
\hline 7 & Worries about negative aspects \\
8 & Insufficient evidence of value \\
9 & Examinations \\
\hline
\end{tabular}

In Europe, research has been conducted for a long time in which advanced technologies or creative concepts are applied to education. 'European School Net (ESN)' is a network that researches and shares these teaching methods, and the Ministry of Education from 34 countries participates. According to a report released by ESN in 2009, the problems arising from the use of games for education are shown in Table 1[18]. The problems introduced in the report are all directly or indirectly related to the selection of games suitable for education. This shortcoming is revealed in the plan to use commercial games, not Serious games developed for education.

\section{Prior research}

In 2005, Akira Baba of Tokyo University began researching with Koei and conducted an experiment in which the online games "Uncharted Waters" and "The Ambition of Nobunaga" were adopted as historical textbooks for the first and second graders. As a result, it was reported that it had a positive effect on improving learning motivation, increasing physical knowledge, raising awareness of the historical era, and improving cooperation/communication ability[19].

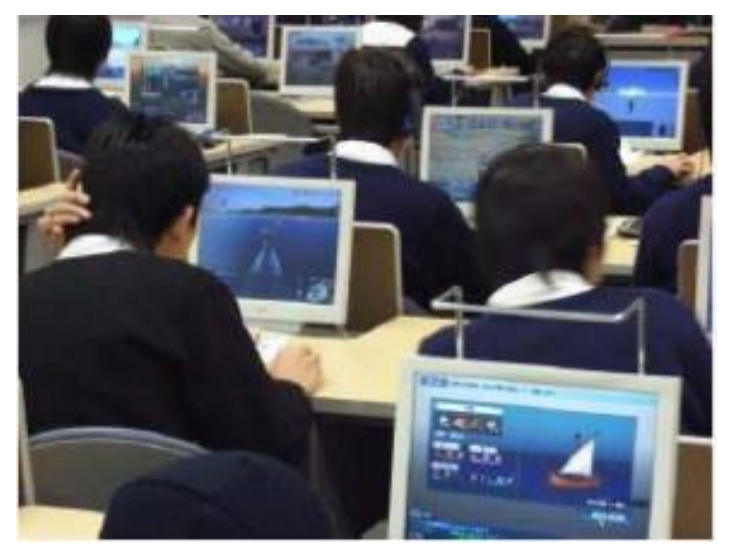

(a)

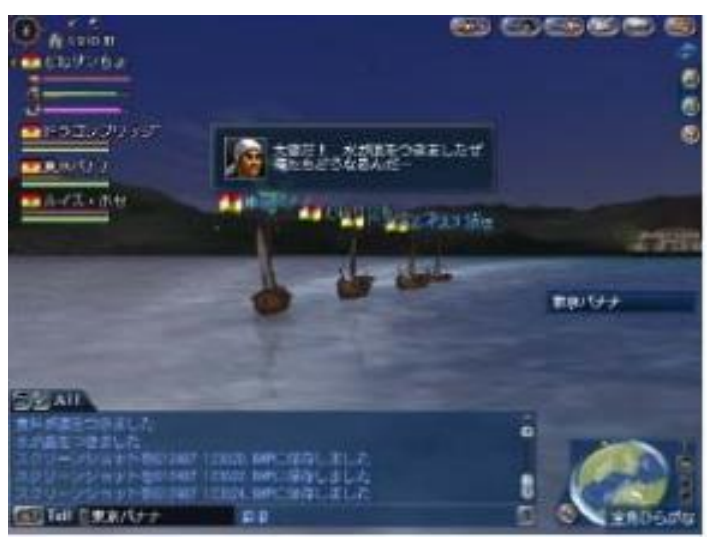

(b)

Figure 1. (a) Class scenery with game-based learning (b) One scene of game 'Uncharted Waters '

At the 2008 Korea-Japan Joint International Symposium on the Utilization of Online Game Education, Professor Akira Baba of Japan demonstrated the effectiveness of indirect history experiences in games, and Professor Jong Hyun Wi of Chung-Ang University defined online games as G-Learning, using 'MapleStory' and 'Online'.

Kim Jin Hyo proved that it contributes to the development of historical thinking skills by applying the simulation game "Civilization 5" to middle school classes and provides opportunities to experience historical events and characters. Although this experiment has side effects that could lead to distortion of students' perception of history, it drew attention by removing anxiety and raising questions about inaccurate reenactments through textbook-linked learning. However, we concluded that since there are practical restrictions for all students to practice in school sites with limited class hours, it is appropriate for exploratory learning activities, but requires a lot of time to achieve results in on-campus classes [20]. Hong Ki-Cheon developed a Serious game for elementary history learning and conducted a study to survey students' satisfaction [21], while Myoun-Jae Lee discussed the process of developing a Serious game for history 
education and method of inducing participation by giving the task of content related to historical events was proposed [22]. In Europe, research on game-based education is active and investment is well conducted. In Scotland, more than 500 teachers participated in the game education project "Consolarium". In Denmark, the trade simulation game "Pattrition 3" was used for history education, and feedback was provided to parents on learning outcomes. "Patition 3 " is a game in which players take on the role of traders and experience the history of Denmark in the Middle Ages [23].

Game-based education appeals more strongly to male students than to female students. A survey conducted by market research firm NPD Group found that male students had a higher level of knowledge of computers and games, but since 2013, female students' interest has been increasing linearly[24], and in simulation-based education, female students are more interested[25]. And a study found that 6 to 12 year old encouraged games to learn about difficult topics, provided an interesting perspective on problem solving, promoted learning and increased interest in topics[26][27][28][29]. Microsoft conducts an educator training program called Microsoft Innovative Education Experience (MIEE). If you apply for the program, it will issue certificates to prove innovative educators. At the same time, Microsoft offers guidelines on creative education, including game-based education[30].

\section{Research}

\subsection{Conditions for selecting games to be studied} follows.

The conditions of the game selected as the research topic in this study are as

1) The background of the times must be clear. Historical elements to be educated through games include characters, culture, and technology. Games with an ambiguous background in the age of the game are not suitable for history education because characters who do not survive simultaneously or the background of the times do not match.

2) There should be no problems with the historical evidence. In most FPS genre games, there is a problem related to firearms, and this part can be skipped personally as the difficulty of the test is high, but it is necessary to be careful because it can instill wrong knowledge into students.

3) There should be no distortion of history. Errors occurring in 1) and 2) above can be corrected by educators in the curriculum, but distortion of history refers to problems that will not end in private affairs. For example, among the games set in the Second World War, there was a game with errors (WW2: Shattered Europe, WW2: Shattered Europe), in which Finland participated in the Allies and Sweden and Spain participated in the Axis. Games that are expected to have fatal side effects when using games with such history distortions for education were excluded from the study.

\subsection{Feasibility Study for Analysis Criteria}

Historical thinking and Re-enaction have been mentioned as a result of a number of historical game-based education studies that have been discussed so far. The Ministry of Education aims to "educate the next generation of historical facts and the historical values inherent in them," so that students can comprehensively grasp the activities of our people and understand today's Korean phenomenon from a historical perspective. To this end, it should be aimed at fostering 'historical thinking' [31]. 
Historical thinking skills are divided into different opinions by historical educators, and it is discussed that both aspects should be maintained in a way that is considered, so attention should be paid to the aspects of 'logical thinking' and the ways to develop 'historical imagination.' The term 're-enaction' is a phenomenology term that means you feel someone else's experience as if you were experiencing it again or as if you were experiencing it again. R.G. Collingwood, a British philosopher of history, is a unique method of history when a historian attempts to conceptualize the past by evidence [32]. However, most of the evidence is not enough or decisive enough to confirm the process of a historical actor's thinking, and humans can all behave differently under the same circumstances, so reconstructing the behavior of a historical actor is the application of one's thinking from the perspective of the actor, based on the assumption that "in these circumstances, that person would have done this." [33]. In fact, dramatization learning, role play, history writing, model making, history trial, history diary, and history drawing can be considered as a way of Re-enactment history learning[34]. In other references, there were cases where history newspapers were published. Lee Myung-hee were defined the four educational effects learned through the experiential historical learning [35].

First, through critical and reflective thinking, the historical behavior that is the subject of learning is not accepted as a fixed one, but can always be selected and developed under one's own control.

Second, by re-enaction of historical behavior, the historical behavior becomes the learner's own behavior, that is, the new historical behavior becomes his own behavior, which means that the learner changes into a new self. Therefore, learners themselves can constantly change according to changes in the historical world.

Third, learning by imaginatively participating in historical behavior enables interaction between historical behavior and learners. Learning and behavior are not separated from knowledge, attitudes, and values, but are integrated into one by an activity called imaginary participation, which means that learning becomes an active process. Furthermore, the learning subject can induce motivation for learning by becoming the subject of close exchange with the learning subject.

As above, through re-enaction history education, students experience more than historical evidence as a subject of learning and'understand' the history at the time of action. Therefore, re-enaction history classes are appropriate for'historical thinking ability', the goal of history education It can be called a teaching method [36].

Among the problems of ESN's Report (Table 1) located in Introduction 1.1, only two or six can be objectified and resolved. Number one is an objective figure, but it is subjective whether it is possible to burden the price. Items 4, 5 and 7 depend on the surrounding environment and teacher personal competence. Insufficient evidence for value 8 is resolved after a long study, but it is not an immediate problem. Test number 9 is also a teacher's role. Therefore, we investigate whether item 2 can be divided into concentration sections based on the 40 minutes of elementary school with the shortest curriculum time, and whether item 6 contains elements that are unreported or inappropriate to teach in addition to the classes classified by the Game Rating and Administration Committee. The background of a history game is the past, but it is different from the genre. Games in each historical background are classified into genres, and Joonho Jang argued that the relationship between the genre of the game and the field of learning was organized as shown in Table 2 [37].

Table 2. Expected learning effect

Genre Expected learning effect




\begin{tabular}{cc}
\hline Role-playing & Ethics and History Learning \\
Simulation & Almost any forms of learning \\
Adventure & Finding suitable games \\
Arcade / Action & Attitudes of other teachers \\
Puzzle & Training and support \\
\hline
\end{tabular}

In this paper, we considered the benefits of the genre and found and selected games that correspond to the three principles described earlier: historical thinking, experiential history learning, time-sharing elements, and Chapter 4.1 above, designed experiments to address the inconvenience introduced in ESN reports.

\subsection{Selected game analysis}

In the ESN report, the difficulty of game-based education was first selected as cost and license. So, when selecting a game for this study, it was selected by considering the price accessibility.

1. Wednesday

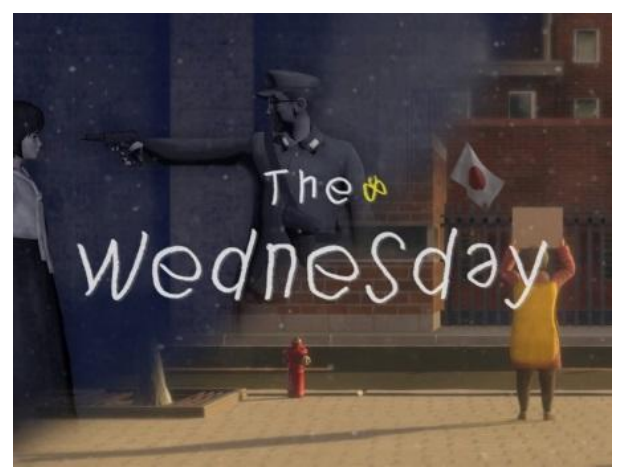

Figure 2. Game 'Wednesday'

- $\quad$ Price accessibility: about $\$ 14$

- $\quad$ Background: Japanese occupation period in 1945

- Description : The grandmother, who was protesting in front of the Japanese Embassy in 1992, suddenly returns to the day before her friends disappeared in 1945. At that time, Grandma, who was a comfort woman in the Japanese military, is a puzzle-type adventure game in which friends find clues about disappearing and find out the truth.

- historical thinking skills : Since it introduces the daily part of the victims of comfort women and the past activities of Japanese imperialism, such as the Japanese Army Unit 731, Maruta, and Unit 1644, it allows us to think about parts not covered in the existing history textbooks.

- re-enaction history learning : It makes you feel like your own story, not someone else's, because you feel that you created the story by direct manipulation. In this immersive situation, I expect to experience empathy and fall.

- Time division : The total play time takes 3 to 5 hours, but since it is composed of several chapters, the education was conducted by teaching one chapter per class.

2. Valiant hearts : The great war 


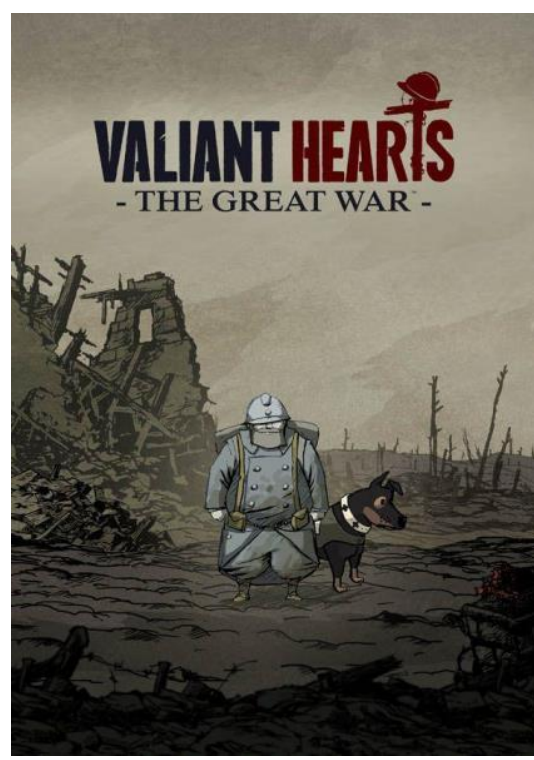

Figure 3. Game 'Valiant hearts : The great war'

- Price accessibility : about $\$ 15$

- Background: First World War

- Description : This game was created as a scenario of an anecdote that would have occurred between 1914 and 1918, when World War I took place. The main character of this game is not a war hero. It contains the contents of the forced recruitment of soldiers living and fleeing in war using the surrounding terrain. In the process, all of his companions are killed by guns or shells, showing the tragedy of war.

- historical thinking skills : The game begins with the assassination of Franz Ferdinand, just like in real history. With the history of Germany's declaration of war on Russia, the protagonist, an ordinary farmer in France, is drafted into the army and the game begins. Based on the historical facts that emerged in this process, it is possible to draw interest in World War I, and to induce the conscripted protagonist to empathize with the pain of the war through his victims while surviving the war.

- re-enaction history learning : Since the protagonist is an ordinary citizen, it is expected that students' empathy can be drawn out, and through this, an experiential history learning will be made.

- Time division : The flow of the game starts with a story and cycles through puzzleaction-story. Using this point, the rotation of one cycle was distributed as one training.

\section{Discussion}

In this paper, 32 sixth graders in elementary school, who do not show much interest in history, were divided into two game education groups and two textbook education groups, and conducted an hour and a half a week for a total of six hours. There were 4 teachers who participated in the class, and each did not teach in one group, but instead taught in a different group every week to experience both teaching methods.

In the game education group, the teacher played the game for two weeks. When explaining the background, it is important for the students to look at the same screen and focus on them, so they did not use the way they play the game. After that, for the remaining two weeks, I was allowed to study using only middle school history textbooks. The rest of the group studied the same range from the first week using textbooks. Among middle school history textbooks, the scope of study was educated by 
selecting 'World War and Social Change' in world history and 'Chosun Society's Change' in Korean history, which are related to the game background.

Table 3. Class method for each week

\begin{tabular}{ccc}
\hline Time & Game-based education & Expected learning effect \\
\hline 1 & Used Games 'Wednesday' & Used Korean history textbook \\
2 & Used Korean history textbook & \\
3 & Used Games ' Valiant Hearts ' & Used World history textbook \\
4 & Used World history textbook & \\
\hline
\end{tabular}

Each textbook consists of six contents, and it is ideal to spend four weeks per unit considering the vacation and exam period of students, so the experiment period was selected as four weeks.

Table 4. contents by each textbook

\begin{tabular}{cc}
\hline World history & Korean history \\
\hline $\begin{array}{c}\text { The emergence of civilization and the } \\
\text { formation of the ancient world }\end{array}$ & $\begin{array}{r}\text { Prehistoric culture and the formation of } \\
\text { ancient countries }\end{array}$ \\
$\begin{array}{c}\text { The spread of world religions and the } \\
\text { formation of local cultures } \\
\text { Exchange and change in the local } \\
\text { world }\end{array}$ & $\begin{array}{r}\text { The delopment of the era of the north } \\
\text { and south countries }\end{array}$ \\
$\begin{array}{c}\text { Imperial invasion and movement to and transition of Goryeo } \\
\text { build a nation-state }\end{array}$ & $\begin{array}{c}\text { Establishment and development of } \\
\text { Joseon }\end{array}$ \\
$\begin{array}{c}\text { World War and Social Change } \\
\text { Development and challenges in the } \\
\text { modern world }\end{array}$ & The development of modern society \\
\hline
\end{tabular}

Each group kept each other secret about how to study, and instructed teachers to have at least five minutes of question-and-answer time, up to 30 minutes, and to record questions related to the class. As a result, the group with game-based training remained at a high level of questions and discussion time, while the group trained with textbooks from the beginning gradually decreased in number and time.

Table 5. Count of questions and discussion time of each group

\begin{tabular}{ccccc}
\hline & \multicolumn{2}{c}{ Game-based education } & \multicolumn{2}{c}{ Only textbook education } \\
\hline Time & Question count & Discussion time & Question count & Discussion time \\
\hline 1 & 11 & 18 & 9 & 15 \\
2 & 13 & 21 & 6 & 10 \\
3 & 11 & 16 & 4 & 6 \\
4 & 14 & 22 & 4 & 8 \\
\hline
\end{tabular}

After the fourth week of the experiment, four teachers were asked a subjective questionnaire asking for keywords about inconveniences in game-based classes, and asked about the adoption of game-based education in education after the experiment.

Table 6. inconvenience survey

Inconvenience Survey

Limitation of the range of history that can be explained through game stories

The ratio of time required for education in the game and time required for nonessential parts 
Progress deviation from game experience

Long play time compared to short class time

Game-based classes were conducted by a teacher playing games and giving an extra speech. The reasons for this experiment were designed in consideration of the universal class environment. In general, classes held at schools involve one teacher dealing with multiple students. When many students play games, the speed of progress is different from each other, which causes the teacher to have to explain several times.

In addition, there are many cases where there are no facilities to allow several students to play games in the first place. Therefore, the speed of the class depends on the speed of the teacher's game, which is not a problem of game-based learning because it depends on the teacher's ability not only in game-based classes but also in textbookoriented classes. The problem that the range of history that can be explained is limited because the game story is limited is also a limitation of all content used in the game, but content delivered through screen media such as movies and dramas can be selected relatively variously. This is because the game industry has a shorter development period than other contents and it is difficult to produce based on true stories, so the number of suitable games is small.

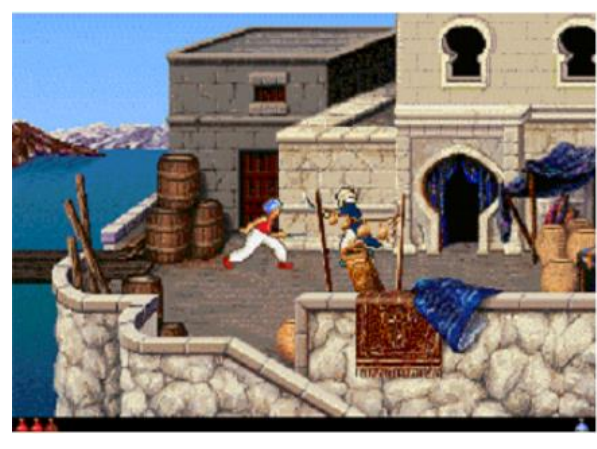

(a)

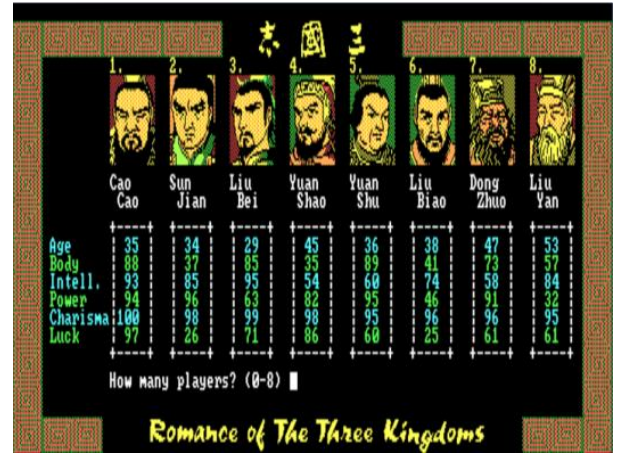

(b)

Figure 4. (a) Prince of Persia(1990) (b) Romance of the three kingdoms(1985)

There are also many historical games developed in the 20th century, but it was not easy to use them for other purposes than game purposes. For example, Figure 5's "Prince of Persia" is based on the culture of Middle Eastern countries, but lacks storytelling, and Figure 6's "Romance of the Three Kingdom" is a famous historical material called IP, but it is not true. Man-Ki Moon surveyed game consumers in their teens to 30s for a total of 68 games, of which 44 games were developed based on real history and background, accounting for about $65 \%$. In particular, $92 \%$ of games developed in the United States and $100 \%$ of games developed in Germany were based on real history[38]. And Korean history game was characterized by multi-play and expressing the economic situation of the era as well as combat in the game[39].

\section{Conclusions}

The importance of history education is always being emphasized, and the effectiveness of game-based education is continuously verified through other studies. In the case of advanced countries in Europe, the United States, and Japan, various attempts have been made to game-based education in regular classes since a decade ago, while education using games in Korea is in a state of inadequate development.

Ah Ram Lee surveyed 83 elementary school teachers about their intention to use game-based learning classes, with $56 \%$ of teachers agreeing to the use of game-based learning, and $15.4 \%$ of those who objected. The demand for learning was more than three times higher [40]. It is regrettable that markets with solid demand are not 
practically utilized for regular classes. This study, which began with the hope of solving the inconvenience of teachers who used the game as educational material, focused on solving the problem based on what was reported in the ESN report. One of the most appropriate subjects when using games as education is history, so historical game selection criteria and evaluation indicators were set for the experiment, and experiments were conducted on elementary school students. Different games have different elements that can be used in education. As one of the ways to solve the 'teacher's hard work' mentioned in the inconvenience of educators, I would like to present examples of using various games in this paper by combining games with various elements. If more historical games can be developed and studied and used in education, the perception of viewing games will ultimately change more positively than before, just as students who have seen historical dramas or movies are more interesting when they see such times in history books.

Author Contributions: Conceptualization, W.H.L.; methodology, W.H.L.; validation, S.Y.P.; formal analysis, W.H.L., S.Y.P. and W.H.L.*; investigation, W.H.L.; writing-original draft preparation, W.H.L.; writing - review and editing, W.H.L., W.H.L.* and S.Y.P.; supervision, W.H.L.* All authors have read and agreed to the published version of the manuscript.

Funding: This work was supported by the Ministry of Education of the Republic of Korea and the National Research Foundation of Korea (2019S1A5C2A04082405)

Institutional Review Board Statement: Not applicable.

Informed Consent Statement: Informed consent was obtained from all subjects involved in the study.

Data Availability Statement: Not applicable.

Acknowledgments: This work was supported by the Ministry of Education of the Republic of Korea and the National Research Foundation of Korea (2019S1A5C2A04082405)

Conflicts of Interest: The authors declare no conflict of interest.

\section{References}

1. Wi, J.H.; Cho, D.Y. The Effect of G-Learning Towards a Student's Affective Domain in Math Subject. Journal of the Korean Game Society 2020, 10, 37-45.

2. Wi, J.H.; Won, E.S. Suggesting effectiveness of G-Learning English afterschool program in elementary schools. The Korea Association of Foreign Languages Education 2014, 21, 137-163.

3. Wi, J.H.; Oh, N.R. The effects of economy education through MMORPG. Journal of the Korean Game Society 2005, 5, 13-22.

4. Wi, J.H.; Won, E.S. The n Utilizing an Online Game, 'Goonzu'. Journal of the Korean Game Society 2009, 9, 83-93.

5. Kim, Y.J. The root cause of tension and immersion: why you have to immerse yourself in the game. Journal of Digital Storytelling Research 2006, 1, 1-14.

6. Juho, H.; Koivisto, J.; Sarsa, H. Does Gamification Work? A Literature Review of Empirical Studies on Gamification. In 47th Hawaii International Conference on System Sciences; HICSS: Waikoloa, HI, USA, 2014, 14, 3025-3034.

7. Prensky, M. Digital Game-Based Learning. New York: McGraw-Hill, 2001.

8. Chen, P.C. New trend of electronic textbooks. Educ. Mon. 2010, 516, 36-40.

9. Alvarez, J; Djaouti, D. An introduction to Serious game Definitions and concepts. Serious Games E Simulation for Risks Management 2011, 11, 11-15.

10. Han, H.W. Conceptual definition and types of Serious games, Humanities Content 2010, 19, 219-236.

11. Kaasinen, A. Plant Species Recognition Skills in Finnish Students and Teachers. Educ. Sci. 2019, 9, 85

12. Chen, M.H.M.; Tsai, S.T.; Chang, C.C. Effects of Game-Based Instruction on the Results of Primary School Children Taking a Natural Science Course. Educ. Sci. 2019, 9, 79.

13. Goo, Y.O. The Effects of Teaching English Vocabulary Reading through Educational Computer Games on Learning Achievement and Interest. Master's thesis, ChungAng University, Korea, 2006

14. Wi, J.H.; Song, I.S. Use of G-Learning Contents as Learning Tools and Analysis of Learning Effects: Focusing on the Application of Elementary School Mathematics, Journal of the Korean Game Society2011, 11, 55-62.

15. Lim, S.Y. A Study on the Effect of English Reading Instruction with the Application of Computer Games on Children's Achievement and Interest of English Reading to 4th Grade Children in the Elementary School, Journal of the English Linguistic Science Association of Korea, 2006, 1-18 
16. Yoon, H.S. A Study on the History and Development Direction of Korean Educational Serious Games, Journal of the Korean Game Society2020, 20, 101-110.

17. Jeong, E.J.; Lee, H.R. A Study on the Concepts and Categorization of Serious Games Based on Strategic Purposes and Applied Theories. Journal of Korean Society for Computer Game 2013, 26, 61-69.

18. Felicia, P. Digital games in schools.; European Schoolnet: Brussels, Belgium, 2009; pp.1-41

19. Japan Machinery Industry Association. 2007 Serious Game Status Survey Report.; Digital Contents Association Foundation: Tokyo, Japan, 2008; pp.66-95

20. Kim, J.H.; Kim, H.S. Essay on the Possibility for Grafting Computer Simulation Game on the Historical Education : The Case of $\ulcorner$ Civilization 5$\lrcorner$. Master's thesis, Hanyang University, Korea, 2014.

21. Hong, K.C.; Jin, S.D. Design and Implementation of a RPG edugame for Learning of History in Elementary School. Journal of the Society for Information Education 2006, 10, 327-340.

22. Lee, M.J.; Kim, K.N. A Serious Game Development for Historical Education Using OGRE Engine. Journal of the Korean Digital Contents Society 2010, 11, 385-392.

23. Game Partition 3 Download Site(Steam). Available online: https://store.steampowered.com/app/33570/Patrician_III/ (accessed on 15 December 2020).

24. Mazurek, M.O.; Engelhardt, C.R. Video game use in boys with autism spectrum disorder, ADHD, or typical development. Pediatrics 2013, 132, 260-266.

25. Kron, F.W.; Gjerde, C.L.; Sen, A.; Fetters, M.D. Medical student attitudes toward video games and related new media technologies in medical education. BMC Med. Educ. 2010, 10, 50.

26. urguillo, J.C. Using game theory and competition-based learning to stimulate student motivation and performance. Comput. Educ. 2010, 55, 566-575.

27. Dickey, M.D. Murder on Grimm Isle: The impact of game narrative design in an educational game-based learning environment. Br. J. Educ. Technol. 2011, 42, 456-469.

28. Ebner, M.; Holzinger, A. Successful implementation of user-centered game based learning in higher education: An example from civil engineering. Comput. Educ. 2007, 49, 873-890.

29. Fengfeng, K. Alternative goal structures for computer game-based learning. Int. J. Comp. Support. Collab. Learn. 2008, 3, 429445.

30. Microsoft Educator Center. Available online: https://education.microsoft.com/ko-kr/library?contentType=learningPath / (accessed on 27 February 2021).

31. Ministry of Education. High School Social Studies Curriculum Commentary.; Ministry of Education: Seoul, Korea, $1995 ;$ pp.169

32. Collingwood, R.G. The Idea of History, Oxford : Oxford University Press, 1966. p.269.

33. Dray, W.H. History as Re-enactment, Oxford: Clarendon Press, 1995. p.53.

34. Kim H.J. Re-enactment, Is it an alternative history teaching method?, National History Teachers' Meeting, History Education 49, 2000.

35. Lee, M.H. Possibility of Chu experience as a way of learning history. Journal of the Korean Society for Social Studies Education Research 1998, 31, 133-157.

36. Kim, B.M. Types and uses of empirical history learning in history education. Master's Thesis, Kookmin University, Korea, 2006.

37. Jang, J.H.; Lee, A.J. Design of educational network game for elementary history learning. Winter Academic Papers of Korean Society for Information Education 2002.

38. Moon, M.K.; Kim, T.Y. Research on the development process and planning elements of digital games based on historical materials, Journal of Broadcast Engineering Society 2007, 12, 460-479.

39. Perkins. D. N. Technology meets constructivism, Educational Technology 1991, 18-23

40. Jeong, E.J.; Lee, H.R. Study on Teacher Awareness and Application Plan for Game-based Learning in Elementary School. The Korean Society for Computer Education 2016, 20, 55-58. 